\title{
Use of proton pump inhibitors and risk of hip fracture in relation to dietary and lifestyle factors: a prospective cohort study
}

\author{
(c) (1) ()
}

\author{
Hamed Khalili clinical and research fellow ${ }^{1}$, Edward S Huang clinical and research fellow ${ }^{1}$, Brian \\ C Jacobson attending physician ${ }^{2}$, Carlos A Camargo Jr attending physician, associate professor ${ }^{34}$, \\ Diane Feskanich assistant professor ${ }^{4}$, Andrew T Chan attending physician, associate professor ${ }^{14}$
}

${ }^{1}$ Gastroenterology Unit, Massachusetts General Hospital, 55 Fruit Street, GRJ-728A, Boston MA 02114, USA; ${ }^{2}$ Section of Gastroenterology, Boston University Medical Center, Boston MA 02118; ${ }^{3}$ Department of Emergency Medicine, Massachusetts General Hospital, Boston MA 02114; ${ }^{4} \mathrm{Channing}$ Laboratory, Department of Medicine, Brigham and Women's Hospital and Harvard Medical School, Boston MA

\begin{abstract}
Objective To examine the association between chronic use of proton pump inhibitors (PPIs) and risk of hip fracture.

Design Prospective cohort study.

Setting Nurses' Health Study, which originally recruited from the 11 most populous states in the US.

Participants 79899 postmenopausal women enrolled in the Nurses' Health Study who provided data on the use of PPIs and other risk factors biennially since 2000 and were followed up to 1 June 2008.

Main outcome measure Incident hip fracture

Results During 565786 person years of follow-up, we documented 893 incident hip fractures. The absolute risk of hip fracture among regular users of PPIs was 2.02 events per 1000 person years, compared with 1.51 events per 1000 person years among non-users. Compared with non-users, the risk of hip fracture among women who regularly used PPIs for at least two years was 35\% higher (age adjusted hazard ratio 1.35 (95\% confidence interval 1.13 to 1.62$)$ ), with longer use associated with increasing risk $\left(P_{\text {trend }}<0.01\right)$. Adjustment for risk factors, including body mass index, physical activity, and intake of calcium did not materially alter this association (hazard ratio 1.36 (1.13 to 1.63)). These associations were also not changed after accounting for reasons for PPI use. The relation between PPI use and fracture differed by smoking history $\left(P_{\text {interaction }}=0.03\right)$. Among current and former smokers, PPI use was associated with greater than $50 \%$ increase in risk of fracture, with a multivariate hazard ratio for fracture of 1.51 (1.20 to 1.91). In contrast, among women who never smoked there was no association (multivariate hazard ratio 1.06 (0.77 to 1.46$)$ ). In a meta-analysis of these results with 10 prior studies, the pooled odds ratio of hip fracture associated with PPI use was 1.30 (1.25 to 1.36).
\end{abstract}

Conclusion Chronic use of PPIs is associated with increased risk of hip fracture, particularly among women with a history of smoking.

\section{Introduction}

Proton pump inhibitors (PPIs) are among the most commonly used drugs worldwide. ${ }^{1}$ In the US, PPI use increased dramatically since 2003 after the Food and Drug Administration approved the drugs for "over the counter" use. Primarily used for the treatment of heartburn symptoms, gastroesophageal reflux, or peptic ulcer, PPIs antagonise hydrogen-potassium adenosine triphosphatase pumps located on gastric parietal cells, ${ }^{2}$ thereby reducing acid production to a greater extent than histamine receptor-2 $\left(\mathrm{H}_{2}\right)$ blockers. ${ }^{3}$ Although short term use of PPIs is generally well tolerated, concern has grown over potential association between long term use and bone fractures, especially of the hip, which are known to be associated with substantial morbidity and mortality. ${ }^{4-6}$ PPIs may inhibit calcium absorption, ${ }^{7}$ directly interfere with osteoclast function, ${ }^{8}$ or induce hypergastrinaemia, resulting in reductions in bone mineral density related to hyperparathyroidism. ${ }^{9}$

Several studies have investigated the association between PPI use and risk of hip fracture. ${ }^{30-17}$ Many of these studies have had important limitations, including retrospective design, ${ }^{10} 12-141617$ inability to control for important dietary and lifestyle confounders, ${ }^{3}{ }^{10}{ }^{12-14}{ }^{16}$ small sample size, ${ }^{17}$ and limited ascertainment of PPI exposure. ${ }^{11}$ None the less, in May 2010 the Food and Drug Administration issued a warning regarding a potential association, but acknowledged that more data were needed. ${ }^{18}$ 
We therefore sought to examine the association between long term PPI use and risk of hip fracture among postmenopausal women enrolled in a large prospective cohort, the Nurses' Health Study, where detailed information about dietary and lifestyle factors are collected biennially. ${ }^{19-23}$ This cohort offered us an opportunity to examine PPI use in the context of other dietary and lifestyle risk factors that may either confound or modify its association with fracture. We also conducted a systematic review of our findings with prior studies to provide a more comprehensive estimate of the association.

\section{Methods}

\section{Study population}

The Nurses' Health Study is a prospective cohort that began in 1976 when 121700 US female registered nurses aged 30-55 years completed a mailed health questionnaire. We sent questionnaires to study participants every two years to update information and identify new cases of fracture; follow-up has consistently exceeded $90 \%$. A validated assessment of physical activity is administered every two years, ${ }^{24}$ and a validated semi-quantitative food frequency questionnaire is administered every four years. ${ }^{25}$ The institutional review board at the Brigham and Women's Hospital approved this study.

\section{Outcome ascertainment}

In 1982 participants were first asked to report all previous hip fractures (date, bone site, and circumstances). Subsequently, in each biennial questionnaire, women were specifically asked, "Over the past two years have you had a hip fracture?" Participants who responded "yes" received a follow-up questionnaire asking them to "describe the circumstances that caused the hip fracture, bone site, and the month/year of fracture." We included cases of hip fracture that were associated with reports of low or moderate trauma (such as slipping on ice or falling from the height of a chair). We excluded fractures associated with high trauma (such as from skiing or falling down a flight of stairs-about $15 \%$ of the reports). In an analysis of 30 study participants, all self reported fractures were validated by medical record review. ${ }^{27}$

\section{Assessment of proton pump inhibitor and $\mathrm{H}_{2}$ blocker use}

In 1994 participants were asked whether they had regularly used "cimetidine (Tagamet) or ranitidine (Zantac)" over the previous two years. In the 1996, 1998, and 2000 questionnaires, participants were asked whether, over the previous two years, they had regularly used "cimetidine (Tagamet) or other $\mathrm{H}_{2}$ blockers (e.g. Zantac, Pepcid, etc).” In 2002, 2004, and 2006 participants were asked whether, over the previous two years, they had regularly used any " $\mathrm{H}_{2}$ blockers (e.g. Zantac, cimetidine, Pepcid, Axid, etc.).” In 2000 and 2002 participants were asked whether, over the previous two years, they had regularly used "Prilosec or Prevacid." In 2004 and 2006, participants were asked whether, over the previous two years, they had regularly used "Prilosec, Prevacid (lansoprazole), Protonix, Nexium, or Aciphex." Women were not asked about dose or to specify the brand or type of PPI.

\section{Other covariates}

On each biennial questionnaire, women were asked about their menopause status; body weight; time spent in recreational and leisure time activities; smoking status; alcohol use; daily cigarette consumption; use of hormone replacement therapy, thiazide diuretics, corticosteroids, bisphosphonates, and calcium supplements; and incident diagnosis of osteoporosis. Participants' self reported body weight and physical activity have been previously validated. ${ }^{28}$ Using a validated semi-quantitative food frequency questionnaire, ${ }^{25}{ }^{26} \mathrm{we}$ calculated total intake of calcium and vitamin D from the reported consumption of foods and use of multivitamins and specific vitamin and mineral supplements. As in previous analyses, we used cumulatively averaged nutrient intake, body weight, and physical activity to reduce within person variation and to reflect long term exposure. ${ }^{29} \mathrm{We}$ included these variables according to categories which we have previously shown to be most strongly associated with risk of hip fracture. ${ }^{21} 2930$

\section{Reasons for PPI use}

We considered the possibility that the previously observed association between PPI use and risk of hip fracture could be related to the reason for use of the drug. In 2000, a supplemental questionnaire that inquired about the frequency, severity, and duration of heartburn and acid regurgitation was sent to 11080 participants in the Nurses' Health Study with asthma and chronic obstructive pulmonary disease and 11080 randomly selected controls (response rate $86 \%, n=19060) .{ }^{30}$ Detailed description and validation of this questionnaire were previously reported. ${ }^{29}$ Among the respondents, 16478 provided complete information regarding PPI use and the reasons for it and therefore were eligible for our analysis.

\section{Statistical analysis}

At baseline, we included postmenopausal women who returned the 2000 biennial questionnaire in which they were first specifically queried about their use of PPIs. We excluded participants who had previously reported hip fracture or cancer. After these exclusions, 79899 women were eligible for analysis. Person time for each participant was calculated from the date of return of the baseline questionnaire to the date of first hip fracture, date of last questionnaire report, death from any cause, or last day of outcome ascertainment (1 June 2008), whichever came first. Women were defined as PPI users if they responded that they had regularly used PPI in the previous two years. We also assessed consistent use by restricting our analysis to follow-up after 2002 and examining women who reported regular PPI use on the two previous questionnaires (that is, 2000 and 2002 at baseline) compared with women who did not report use on these questionnaires. ${ }^{31}$

We used Cox proportional hazards modelling using time varying variables with the most updated information for PPI use and other covariates before each two year interval to calculate adjusted hazard ratios and $95 \%$ confidence intervals. We also examined the association between PPI use and hip fracture according to strata of other risk factors. We used SAS version 9.1.3 (Cary NC, USA) for these analyses. All P values were two sided, and values $<0.05$ were considered statistically significant.

\section{Systematic review of results with prior studies}

We also conducted a meta-analysis of our data with the results of published studies assessing the relation between chronic PPI use and risk of hip fracture. We included the seven studies that were cited by the Food and Drug Administration in the May 2010 report. ${ }^{18}$ In addition, we conducted a Medline search (last accessed 20 December 2010) with the search terms "proton pump inhibitor" AND "fracture" and identified four additional studies for inclusion. ${ }^{12}{ }^{32-34} \mathrm{We}$ excluded the study by Roux et $\mathrm{al}^{34}$ since the primary outcome was vertebral fracture and there 
were only 11 cases of hip fracture reported. In addition, three studies $^{316} 32$ used the UK General Practice Research Database, although there may have been differences in the populations included. Thus, we included all three studies in our meta-analysis but also conducted sensitivity analyses in which we computed the pooled odds ratio with inclusion of only one of the three studies each in turn.

We used the adjusted odds ratio for hip fracture as our metameter of interest. However, in two studies, data were reported only as adjusted hazard ratios. For the study by Gray et al, ${ }^{11}$ we estimated the odds ratio by calculating the numbers of cases in the control and exposed groups using the reported incident rate and person time. For the study by $\mathrm{Yu}$ et al, ${ }^{17}$ because the number of cases of fracture was not reported or provided by the authors after our request, we used the reported hazard ratio. We pooled estimates by random effects meta-analysis according to the method of Desimonian and Laird. ${ }^{35}$ We used the Q statistic to estimate heterogeneity among the studies. We used Comprehensive Meta-Analysis software (Biostat, Englewood NJ, USA) for these analyses (see appendix on bmj.com).

\section{Results}

Among 79899 postmenopausal women, we documented 893 incident hip fractures over 565786 person years of follow-up. In $2000,6.7 \%$ of women regularly used a PPI, rising to $18.9 \%$ by 2008 . Compared with participants who did not regularly use a PPI, regular users had a higher body mass index, were less physically active, consumed less alcohol, were more likely to have a history of osteoporosis, and were more likely to use hormone replacement therapy, thiazide diuretics, corticosteroids, or bisphosphonates (table $1 \Downarrow$ ).

The absolute risk of hip fracture among regular users of PPIs was 2.02 events per 1000 person years, compared with 1.51 events per 1000 person years among non-users. Compared with non-users, regular users of PPIs had a $35 \%$ increase in risk of hip fracture (age adjusted hazard ratio 1.35 (95\% confidence interval 1.13 to 1.62 )) (table $2 \Downarrow$ ). The relation remained largely unchanged even after adjusting for body mass index (hazard ratio 1.45 (1.21 to 1.73$)$ ) or intake of dietary and supplemental calcium (hazard ratio 1.35 (1.12 to 1.62)). After additionally accounting for other risk factors for fracture - including smoking status, physical activity, and history of osteoporosis-these risk estimates were not materially altered (hazard ratio 1.37 (1.14 to 1.64)). We also did not observe any change in risk after adjusting for concomitant use of drugs known to affect the risk of fracture, including hormone replacement, bisphosphonates, corticosteroids, and thiazide diuretics (fully adjusted multivariate hazard ratio 1.36 (1.13 to 1.63$)$ ).

We first asked participants in the Nurses' Health Study about PPI use in the 2000 questionnaire. We considered the possibility that women who reported use in 2000 had probably used PPIs for varying durations. Thus, we conducted an analysis in which we excluded women who reported use in 2000 and restricted the analysis to follow-up after 2002. Women who first reported PPI use in 2002 had a fully adjusted hazard ratio of hip fracture of 1.42 (1.14 to 1.76) compared with women who had not used PPIs. To test if the association between PPI use and fracture might be due to its effect on gastric acid suppression, we examined regular use of less potent acid suppressors, $\mathrm{H}_{2}$ blockers, in relation to risk of fracture after excluding participants who used PPIs. Compared with PPI use, regular use of $\mathrm{H}_{2}$ blockers was associated with a more modest risk of fracture (fully adjusted hazard ratio 1.23 (1.02 to 1.50$) v$ non-use).

The risk of hip fracture associated with PPI use increased with the duration of use $\left(\mathrm{P}_{\text {trend }}<0.01\right)$ (table $\left.3 \Downarrow\right)$. Compared with non-users, the fully adjusted hazard ratios of fracture were 1.36 (1.12 to 1.65) for women with two years' use of PPIs, 1.42 (1.05 to 1.93) for four years' use, and 1.55 (1.03 to 2.32) for six to eight years' use. To assess consistent use, we focused our analyses on women who reported PPI use in two consecutive biennial follow-up questionnaires and compared the incidence of fracture among women who did not use PPIs in two consecutive intervals. Among consistent users, the fully adjusted hazard ratio of fracture was 1.42 (1.06 to 1.88 ).

We also considered time since stopping PPI use in relation to risk of fracture (table $4 \Downarrow$ ). Although risk persisted for women who stopped PPI use within two years, women who had stopped use more than two years previously had a fully adjusted hazard ratio of fracture of 1.10 (0.63 to 1.92), similar to that of women who had never used a PPI.

We evaluated potential differences in the influence of PPI use according to strata of known risk factors (table $5 \Downarrow$ ). The risk of hip fracture seemed to differ according to history of cigarette smoking $\left(\mathrm{P}_{\text {interaction }}=0.03\right)$. Among women who either previously or currently smoked, the fully adjusted hazard ratio of fracture was 1.51 (1.20 to 1.91). In contrast, there was no significant association between PPI use and risk of fracture among women who never smoked (fully adjusted hazard ratio 1.06 (0.77 to 1.46)). The effect of PPIs was not modified by strata defined by age, body mass index, use of hormone replacement therapy, use of corticosteroids, history of osteoporosis, or intake of calcium (all $\mathrm{P}_{\text {interaction }}>0.10$ ).

We considered the possibility that the observed association of PPIs with hip fracture could be related to the reason for taking the drug. In 2000 we collected detailed information about symptoms of acid reflux and heartburn from 16478 participants through a supplementary questionnaire. Among these participants, the fully adjusted hazard ratio of fracture associated with regular use of PPIs was 1.45 (1.01 to 2.10) and was not materially altered after accounting for the reason for PPI use. Specifically, the fully adjusted hazard ratio of fracture was 1.53 (1.04 to 2.25) after adjusting for heartburn; 1.37 (0.94 to 2.02) after adjusting for acid reflux; and 1.39 (0.96 to 2.02) after adjusting for peptic ulcer disease. These effect estimates did not vary according to the participants' case or control status $\left(\mathrm{P}_{\text {interaction }}=0.57\right)$. Moreover, in separate analyses, there were no independent associations between reported heartburn, acid reflux, or peptic ulcer disease and risk of hip fracture (data not shown). We also conducted several sensitivity analyses to confirm that our associations were robust (see appendix on bmj.com).

\section{Systematic review}

Finally, we performed a systematic review of our results with the 10 published epidemiological studies on risk of hip fracture with chronic use of PPIs (see table in appendix). ${ }^{3} 10-1416173334$ There was moderate heterogeneity across studies $\left(Q_{\text {statistic }}=22.0\right.$; $\mathrm{I}_{2}=50.0, \mathrm{P}=0.02$ ). Among the 1562862 individuals included within the 11 studies, the pooled odds ratio of hip fracture associated with PPI use was 1.28 (1.19 to 1.37) using a random effects meta-analysis (figure $\downarrow$ ). We observed similar results using a fixed effects meta-analysis (odds ratio 1.30 (1.25 to 1.36)). We also computed the pooled odds ratio with inclusion of only one of the three studies from the UK General Practice Research Database each in turn. ${ }^{36}{ }^{162}$ Using a random effects 
meta-analysis, we found the pooled odds ratio of hip fracture associated with PPI use was 1.30 (1.20 to 1.40) including the study of Yang et al, ${ }^{3} 1.27$ (1.18 to 1.36 ) including de Vries et $\mathrm{al}^{32}$ and 1.25 (1.15 to 1.37 ) including Kaye et al. ${ }^{16}$

\section{Discussion}

Findings from this large prospective cohort of postmenopausal women and a systematic review of epidemiological studies show a significant association between regular use of PPIs and risk of hip fracture. Furthermore, our results show that risk increases with longer duration of PPI use and seems to be confined to women with a history of smoking. These associations remained largely unchanged even after carefully adjusting for factors associated with both use of PPI and risk of hip fracture, as well as the reasons for PPI use. The increased risk of hip fracture was no longer evident after PPI use had been stopped for two or more years.

\section{Comparison with other studies}

Our results are supported by several prior findings, including recent meta-analyses. ${ }^{36}$ In two large case-control studies based on the UK General Practice Research Database and the Kaiser Permanente, Northern California, integrated healthcare delivery system, ${ }^{30}$ PPI use for at least one year was associated with an increase in risk of hip fracture of similar magnitude to our risk estimates. Because these case-control studies had limited information on several key risk factors for fracture, our cohort analysis, with careful adjustment for such factors, significantly extends these findings.

Our results do, however, contrast with data from other studies. In an independent analysis of the UK General Practice Research Database, PPI use was not associated with hip fracture. ${ }^{16}$ However, this study was limited to individuals without risk factors for hip fracture. More recently, in the Women's Health Initiative, PPI use was associated with risk of total fracture, spine fracture, and wrist fracture, but not hip fracture or changes in bone mineral density. ${ }^{11}$ However, data on PPI use was collected only in 1997 and 2000, when the prevalence of use was extremely low (2.1\% in 1997, 5.8\% in 2000). By not accounting for the dramatic increase in use of these drugs after 2000, the researchers may have misclassified PPI exposure and led to their finding no association for hip fracture. In support of this explanation, we also observed no significant association with risk of hip fracture when we considered PPI use only according to our baseline assessment in 2000 (multivariate adjusted hazard ratio 1.20 (0.94 to 1.54$)$ ). Moreover, it is possible that the association between PPI and fracture may be mediated independently of changes in bone mineral density.

Consistent with prior studies, ${ }^{3}{ }^{10}$ we did observe a significant, though more modest, association with hip fracture among women who used $\mathrm{H}_{2}$ blockers, which are less potent acid suppressors than PPI. These data suggest mechanistically that PPIs may increase fracture risk through their effect on gastric acid secretion, which could impair absorption of calcium. However, in our analysis, as well as others, ${ }^{11}$ risk of fracture did not seem to be modified by intake of calcium. This is further supported by two recent studies that showed no association between PPI use and gut calcium absorption. ${ }^{38}{ }^{39}$ Moreover, several studies have not observed a significant association between PPI use and short term changes in bone mineral density. ${ }^{11} 1740$

Nevertheless, our finding that the risk of fracture was confined to women with a history of smoking, an established risk factor for fracture, ${ }^{19}$ may provide additional mechanistic insight.
Smoking has been shown to inhibit calcium absorption. ${ }^{41}$ Thus, smoking and PPIs may have a synergistic effect on fracture risk mediated by impaired calcium absorption. In addition, experimental studies have postulated that both PPIs and smoking influence osteoclast function, ${ }^{8}{ }^{42}$ perhaps suggesting a shared negative effect on bone remodelling. Future experimental studies or additional analyses of other cohorts should also examine joint exposure to PPI use and smoking.

\section{Strengths and limitations of the study}

An important strength of our study compared with prior analyses was the detailed, prospectively collected, and validated information on several potential confounding risk factors, including body mass index, use of postmenopausal hormones, smoking, calcium intake, and physical activity. In our cohort, each of these factors has previously been associated with risk of fracture. ${ }^{19-23}$ Thus, we were able to carefully adjust for these potential confounders to determine more clearly the specific effect of PPI use on the risk of fracture. We were also able to minimise confounding by disease indication or protopathic bias by accounting for the clinical reason for PPI use.

Most prior studies, including the two large case-control studies that showed strong associations, ${ }^{3}{ }^{10}$ had a substantial amount of incomplete information on body mass index and smoking and were unable to assess adequately diet, physical activity, and the indication for PPI use. Thus, our results provide additional assurance that these previously reported associations are not due to incomplete adjustment of confounding factors. In our analysis, we also collected information on PPI use every two years and used time-varying PPI exposure in our Cox models. Thus, our study was uniquely able to account for the effect of changes in PPI use and the substantial increase in PPI use over the past decade on risk of fracture, minimising misclassification of exposure. Lastly, despite significant heterogeneity between studies, our systemic review and meta-analysis, which included 1562862 patients, showed consistent results.

Our study has several limitations. Firstly, we did not have information about PPI use in participants before 2000. However, the prevalence of use in 2000 was low (6.7\%) and steadily increased through 2008, reflecting secular trends. Thus, PPI use before 2000 was probably extremely low. None the less, we did observe a significant relation between duration of PPI use and risk of hip fracture; any misclassification of PPI use before 2000 would be expected to attenuate our risk estimates. Moreover, when we limited our analysis to new users of PPI beginning in 2002, we observed similar results.

Secondly, we did not have specific information on the type or brand of PPI and the doses used. However, heterogeneity in risk associated with PPI type or dose would tend to bias our results toward the null. In addition, compared with prescription data, reports of regular use of PPI in the general questionnaire by medical professionals are likely to be a better reflection of the actual intake of the drug.

Thirdly, information about hip fracture is self reported and not confirmed by medical records. However, our validation study showed that self reported hip fracture is extremely reliable in this cohort of medical professionals. Fourthly, we did not have information about bone mineral density, but prior studies have not demonstrated an association between PPI use and changes in bone mineral density. ${ }^{11}{ }^{17} 40$ Fifthly, our study is observational, and we cannot exclude the possibility of residual confounding. However, adjustment for the most important risk factors previously identified for hip fracture did not appreciably alter our results. Moreover, our data are remarkably consistent with 
the risk estimates obtained from a systematic review of prior studies. Finally, because our sample size was large, it is possible that even small differences in the prevalence of risk factors could be statistically significant but may not be clinically significant. However, our associations are reasonable in magnitude, in line with other published estimates, ${ }^{12} 1734$ and biologically plausible.

\section{Conclusion and policy implication}

In summary, regular use of PPI was associated with increased risk of hip fracture among postmenopausal women, with the strongest risk observed in individuals with the longest duration of use or with a history of smoking. Our results, considered in the context of a systematic review of prior studies, provide compelling evidence of a significant association between PPI use and fracture. Furthermore, in view of the steadily growing prevalence of regular PPI use, our estimates of an absolute increase in risk of five hip fractures per 10000 person years associated with PPI use suggest the potential for a high burden of fractures attributable to PPIs across the population. These findings further support the recent decision of the Food and Drug Administration to revise labelling of PPIs to incorporate concerns about a possible increase in risk of fractures with these drugs. ${ }^{18}$ Our data suggest the importance of carefully evaluating the need for long term, continuous use of PPIs, particularly among individuals with a history of smoking.

An abstract of this work was presented in the Distinguished Abstract Plenary of the Clinical Practice Council at the annual meeting of the American Gastroenterological Association on 9 May 2011. The complete manuscript has not been published in any other form.

Contributors: HK was responsible for study concept and design, acquisition of data, analysis and interpretation of data, drafting of the manuscript, critical revision of the manuscript for important intellectual content, and statistical analysis. ESH was responsible for acquisition of data, analysis and interpretation of data, and critical revision of the manuscript for important intellectual content. BCJ was responsible for acquisition of data and critical revision of the manuscript for important intellectual content. CAC was responsible for acquisition of data, analysis and interpretation of data, and critical revision of the manuscript for important intellectual content. DF was responsible for acquisition of data, analysis and interpretation of data, and critical revision of the manuscript for important intellectual content. ATC was responsible for study concept and design, analysis and interpretation of data, drafting of the manuscript, and critical revision of the manuscript for important intellectual content.

Funding: This study was funded by the US National Institutes of Health (grant No NIH R01 CA137178, P01 CA87969). ATC is a Damon Runyon Cancer Research Foundation clinical investigator. BCJ is supported by a grant from the National Institutes of Health (NIH R01 DK088782). HK is supported by a career development award from the IBD Working Group. ESH is supported by a career development award from the American Gastroenterological Association.

Competing interests: All authors have completed the ICMJE uniform disclosure form at www.icmje.org/coi_disclosure.pdf (available on request from the corresponding author) and declare: no support from any organisation for the submitted work; no financial relationships with any organisations that might have an interest in the submitted work in the previous three years; no other relationships or activities that could appear to have influenced the submitted work.

Ethical approval: The institutional review board at the Brigham and Women's Hospital approved this study.
Data sharing: Requests for access to data, statistical code, questionnaires, and technical processes may be made by contacting the corresponding author at achan@partners.org

1 Targownik LE, Metge C, Roos L, Leung S. The prevalence of and the clinical and demographic characteristics associated with high-intensity proton pump inhibitor use. Am J Gastroenterol 2007;102:942-50.

2 Wolfe MM, Soll AH. The physiology of gastric acid secretion. N Engl J Med 1988;319:1707-15

3 Yang YX, Lewis JD, Epstein S, Metz DC. Long-term proton pump inhibitor therapy and risk of hip fracture. JAMA 2006;296:2947-53.

4 Bliuc D, Nguyen ND, Milch VE, Nguyen TV, Eisman JA, Center JR. Mortality risk associated with low-trauma osteoporotic fracture and subsequent fracture in men and women. JAMA 2009;301:513-21.

5 Brauer CA, Coca-Perraillon M, Cutler DM, Rosen AB. Incidence and mortality of hip fractures in the United States. JAMA 2009;302:1573-9.

6 Leibson CL, Tosteson AN, Gabriel SE, Ransom JE, Melton LJ. Mortality, disability, and nursing home use for persons with and without hip fracture: a population-based study. $J$ Am Geriatr Soc 2002;50:1644-50.

7 O'Connell MB, Madden DM, Murray AM, Heaney RP, Kerzner LJ. Effects of proton pump inhibitors on calcium carbonate absorption in women: a randomized crossover trial. $\mathrm{Am}$ J Med 2005;118:778-81.

8 Mizunashi K, Furukawa Y, Katano K, Abe K. Effect of omeprazole, an inhibitor of $\mathrm{H}+, \mathrm{K}(+)$-ATPase, on bone resorption in humans. Calcif Tissue Int 1993;53:21-5.

9 Gagnemo-Persson R, Samuelsson A, Hakanson R, Persson P. Chicken parathyroid hormone gene expression in response to gastrin, omeprazole, ergocalciferol, and restricted food intake. Calcif Tissue Int 1997;61:210-5.

10 Corley DA, Kubo A, Zhao W, Quesenberry C. Proton pump inhibitors and histamine-2 receptor antagonists are associated with hip fractures among at-risk patients. Gastroenterology 2010;139:93-101.

11 Gray SL, LaCroix AZ, Larson J, Robbins J, Cauley JA, Manson JE, et al. Proton pump inhibitor use, hip fracture, and change in bone mineral density in postmenopausal women: results from the Women's Health Initiative. Arch Intern Med 2010;170:765-71.

12 Pouwels S, Lalmohamed A, Souverein P, Cooper C, Veldt BJ, Leufkens HG, et al. Use of proton pump inhibitors and risk of hip/femur fracture: a population-based case-control study. Osteoporos Int 2011;22:903-10.

13 Targownik LE, Lix LM, Metge CJ, Prior HJ, Leung S, Leslie WD. Use of proton pump inhibitors and risk of osteoporosis-related fractures. CMAJ 2008;179:319-26.

14 Vestergaard P, Rejnmark L, Mosekilde L. Proton pump inhibitors, histamine H2 receptor antagonists, and other antacid medications and the risk of fracture. Calcif Tissue Int 2006;79:76-83.

15 Yang YX. Proton pump inhibitor therapy and osteoporosis. Curr Drug Saf 2008:3:204-9.

16 Kaye JA, Jick $\mathrm{H}$. Proton pump inhibitor use and risk of hip fractures in patients without major risk factors. Pharmacotherapy 2008:28:951-9.

17 Yu EW, Blackwell T, Ensrud KE, Hillier TA, Lane NE, Orwoll E, et al. Acid-suppressive medications and risk of bone loss and fracture in older adults. Calcif Tissue Int 2008;83:251-9.

18 FDA. Drug safety communication: possible increased risk of fractures of the hip, wrist, and spine with the use of proton pump inhibitors. 2010. www.fda.gov/Drugs/DrugSafety/ PostmarketDrugSafetyInformationforPatientsandProviders/ucm213206.htm.

19 Cornuz J, Feskanich D, Willett WC, Colditz GA. Smoking, smoking cessation, and risk of hip fracture in women. Am J Med 1999;106:311-4.

20 Feskanich D, Singh V, Willett WC, Colditz GA. Vitamin A intake and hip fractures among postmenopausal women. JAMA 2002;287:47-54.

21 Feskanich D, Willett W, Colditz G. Walking and leisure-time activity and risk of hip fracture in postmenopausal women. JAMA 2002;288:2300-6.

22 Feskanich D, Willett WC, Colditz GA. Calcium, vitamin D, milk consumption, and hip fractures: a prospective study among postmenopausal women. Am J Clin Nutr 2003;77:504-11.

23 Feskanich D, Willett WC, Stampfer MJ, Colditz GA. A prospective study of thiazide use and fractures in women. Osteoporos Int 1997;7:79-84.

24 Wolf AM, Hunter DJ, Colditz GA, Manson JE, Stampfer MJ, Corsano KA, et al. Reproducibility and validity of a self-administered physical activity questionnaire. Int $J$ Epidemiol 1994;23:991-9.

25 Feskanich D, Rimm EB, Giovannucci EL, Colditz GA, Stampfer MJ, Litin LB, et al. Reproducibility and validity of food intake measurements from a semiquantitative food frequency questionnaire. J Am Diet Assoc 1993;93:790-6.

26 Rimm EB, Giovannucci EL, Stampfer MJ, Colditz GA, Litin LB, Willett WC. Reproducibility and validity of an expanded self-administered semiquantitative food frequency questionnaire among male health professionals. Am J Epidemiol 1992;135:1114-26; discussion 1127-36

27 Colditz GA, Martin P, Stampfer MJ, Willett WC, Sampson L, Rosner B, et al. Validation of questionnaire information on risk factors and disease outcomes in a prospective cohort study of women. Am J Epidemiol 1986:123:894-900.

28 Willett W, Stampfer MJ, Bain C, Lipnick R, Speizer FE, Rosner B, et al. Cigarette smoking, relative weight, and menopause. Am J Epidemiol 1983;117:651-8.

29 Hu FB, Stampfer MJ, Rimm E, Ascherio A, Rosner BA, Spiegelman D, et al. Dietary fat and coronary heart disease: a comparison of approaches for adjusting for total energy intake and modeling repeated dietary measurements. Am J Epidemiol 1999;149:531-40.

30 Jacobson BC, Somers SC, Fuchs CS, Kelly CP, Camargo CA Jr. Body-mass index and symptoms of gastroesophageal reflux in women. N Engl J Med 2006;354:2340-8.

31 Chan AT, Giovannucci EL, Schernhammer ES, Colditz GA, Hunter DJ, Willett WC, et al. A prospective study of aspirin use and the risk for colorectal adenoma. Ann Intern Med 2004;140:157-66.

32 De Vries F, Cooper AL, Cockle SM, van Staa TP, Cooper C. Fracture risk in patients receiving acid-suppressant medication alone and in combination with bisphosphonates. Osteoporos Int 2009:20:1989-98.

33 Chiu HF, Huang YW, Chang CC, Yang CY. Use of proton pump inhibitors increased the risk of hip fracture: a population-based case-control study. Pharmacoepidemiol Drug Saf 2010;19:1131-6.

34 Roux C, Briot K, Gossec L, Kolta S, Blenk T, Felsenberg D, et al. Increase in vertebral fracture risk in postmenopausal women using omeprazole. Calcif Tissue Int 2009;84:13-9.

35 DerSimonian R, Laird N. Meta-analysis in clinical trials. Control Clin Trials 1986;7:177-88. 


\section{What is already known on this topic}

Studies exploring the association between use of proton pump inhibitors and hip fracture have produced conflicting results Many studies have limited information on key lifestyle and dietary factors that could influence or modify this association

\section{What this study adds}

Among postmenopausal women, regular use of proton pump inhibitors was associated with a $35 \%$ increased risk of hip fracture The risk seemed to be confined to women with a history of smoking

36 Kwok CS, Yeong JK, Loke YK. Meta-analysis: risk of fractures with acid-suppressing medication. Bone 2011:48:768-76

37 Ngamruengphong S, Leontiadis GI, Radhi S, Dentino A, Nugent K. Proton pump inhibitors and risk of fracture: a systematic review and meta-analysis of observational studies. $A m$ $J$ Gastroenterol 2011;106:1209-18.

38 Hansen KE, Jones AN, Lindstrom MJ, Davis LA, Ziegler TE, Penniston KL, et al. Do proton pump inhibitors decrease calcium absorption? J Bone Miner Res 2010;25:2786-95.

39 Wright MJ, Sullivan RR, Gaffney-Stomberg E, Caseria DM, O'Brien KO, Proctor DD, et al. Inhibiting gastric acid production does not affect intestinal calcium absorption in young, healthy individuals: a randomized, crossover, controlled clinical trial. J Bone Miner Res 2010;25:2205-11.

40 Targownik LE, Lix LM, Leung S, Leslie WD. Proton-pump inhibitor use is not associated with osteoporosis or accelerated bone mineral density loss. Gastroenterology 2010;138:896-904.

41 Krall EA, Dawson-Hughes B. Smoking increases bone loss and decreases intestinal calcium absorption. J Bone Miner Res 1999;14:215-20.
42 Liu X, Kohyama T, Kobayashi T, Abe S, Kim HJ, Reed EC, et al. Cigarette smoke extract inhibits chemotaxis and collagen gel contraction mediated by human bone marrow osteoprogenitor cells and osteoblast-like cells. Osteoporos Int 2003;14:235-42.

\section{Accepted: 06 November 2011}

\section{Cite this as: BMJ 2012;344:e372}

This is an open-access article distributed under the terms of the Creative Commons Attribution Non-commercial License, which permits use, distribution, and reproduction in any medium, provided the original work is properly cited, the use is non commercial and is otherwise in compliance with the license. See: http://creativecommons.org/licenses/bync/2.0/ and http://creativecommons.org/licenses/by-nc/2.0/legalcode. 


\section{Tables}

Table 1| Baseline characteristics of 79899 postmenopausal women enrolled in the Nurses' Health Study according to use of proton pump inhibitors (PPIs) in 2000. Values are numbers (percentages) unless stated otherwise, and all variables are age adjusted (standardised to the age distribution of the study population)

\begin{tabular}{|c|c|c|}
\hline & Non-user of PPIs ( $n=74558)$ & Regular PPI user $(n=5341)$ \\
\hline Mean (SD) age (years) & $66.6(6.9)$ & $67.0(7.0)$ \\
\hline Mean (SD) body mass index $\left(\mathrm{kg} / \mathrm{m}^{2}\right)$ & $26.6(5.2)$ & $28.2(5.6)$ \\
\hline \multicolumn{3}{|l|}{ Smoking status*: } \\
\hline Never & $32983(44.3)$ & $2194(41.2)$ \\
\hline Former use $\geq 10$ years & $28100(37.7)$ & $2204(41.3)$ \\
\hline Former use $<10$ years & $6411(8.6)$ & $544(10.2)$ \\
\hline Current use $<15$ cigarettes/day & $3399(4.5)$ & $202(3.7)$ \\
\hline Current use $\geq 15$ cigarettes/day & $3492(4.7)$ & $185(3.4)$ \\
\hline Missing data $†$ & $173(0.2)$ & $12(0.2)$ \\
\hline Mean (SD) physical activity (METs-hour/week) $\ddagger$ & $17.7(15.6)$ & $14.5(13.2)$ \\
\hline Mean (SD) Alcohol intake (g/day)§ & $5.6(8.5)$ & $4.7(7.7)$ \\
\hline Mean (SD) Calcium intake (mg/day)§ & $982(341)$ & $1001(347)$ \\
\hline \multicolumn{3}{|l|}{ Use of hormone replacement therapy: } \\
\hline Current & $32234(43.2)$ & $2570(48.1)$ \\
\hline Former or never & $37920(50.9)$ & $2481(46.5)$ \\
\hline Missing data† & $4404(5.9)$ & $290(5.4)$ \\
\hline History of osteoporosis & 22.0 & 31.0 \\
\hline Use of bisphosphonate & 6.0 & 7.0 \\
\hline Use of corticosteroid & 5.0 & 11.0 \\
\hline Use of thiazide & 15.0 & 24.0 \\
\hline Mean (SD) vitamin D intake (IU/day)§ & $443(265)$ & $461(274)$ \\
\hline
\end{tabular}

$\mathrm{SD}=$ standard deviation. METs=metabolic equivalents.

*Categories were selected based on prior studies.

†The missing data category could not be included in our multivariate models because the numbers of participants in the missing categories were too low. Thus, in our models we carried forward values from prior questionnaires.

$\ddagger 381$ participants did not complete the physical activity assessment. For these participants, we assigned the median value of physical activity derived from the entire cohort.

$\$ 1443$ did not complete the semi-quantitative food frequency questionnaire. For these participants, we assigned the median value of calcium, alcohol, and vitamin $\mathrm{D}$ derived from the entire cohort. 
Table 2| Risk of hip fracture according to use of proton pump inhibitors (PPIs) among 79899 postmenopausal women enrolled in the Nurses' Health Study

\begin{tabular}{|c|c|c|}
\hline & Non-users of PPIs & Regular PPI user \\
\hline No of cases/No of person years & $744 / 492154$ & $149 / 73632$ \\
\hline \multicolumn{3}{|l|}{ Hazard ratio $(95 \% \mathrm{Cl})$ : } \\
\hline Adjusted for age & 1.00 & $1.35(1.13$ to 1.62$)$ \\
\hline Adjusted for age + body mass index ${ }^{*}$ & 1.00 & $1.45(1.21$ to 1.73$)$ \\
\hline Adjusted for age + calcium intake $†$ & 1.00 & 1.35 (1.12 to 1.62$)$ \\
\hline Multivariable adjusted $\ddagger$ & 1.00 & $1.37(1.14$ to 1.64$)$ \\
\hline Fully adjusted§ & 1.00 & $1.36(1.13$ to 1.63$)$ \\
\hline
\end{tabular}

*Body mass index categorised as <20, 20-24.9, 25-29.9, $\geq 30 \mathrm{~kg} / \mathrm{m}^{2}$.

$\dagger$ †nergy adjusted calcium intake calculated from diet and dietary supplements, categorised as <600, 600-899, 900-1200, >1200 mg/day.

$\ddagger$ Adjusted for age (months), body mass index, alcohol intake $(<5,5-15,>15 \mathrm{~g} /$ day), total energy adjusted calcium intake, level of physical activity $(<1.7,1.7-4.5$, 4.6-10.6, 10.7-22.1, >22.1 metabolic equivalents-hours/week), smoking status (never, past $\geq 10$ years, past $<10$ years, current $<15$ cigarettes/day, current $>15$ cigarettes/day), vitamin D intake (<400,400-600, >600 IU/day), and history of osteoporosis (yes, no).

§Adjusted for age (years), body mass index, alcohol intake, total energy adjusted calcium intake, history of osteoporosis, level of physical activity, smoking status, vitamin D intake, bisphosphonate use (yes, no), thiazide use (yes, no), corticosteroid use (yes, no), and use of postmenopausal hormone replacement therapy (never, past, current). 
Table 3| Risk of hip fracture according to duration of use of proton pump inhibitors (PPIs) among 79899 postmenopausal women enrolled in the Nurses' Health Study

\begin{tabular}{|c|c|c|c|c|c|}
\hline & \multicolumn{4}{|c|}{ No of years of regular PPI use ${ }^{*}$} & \multirow[b]{2}{*}{$P_{\text {trend }} t$} \\
\hline & 0 & 2 & 4 & $6-8$ & \\
\hline $\begin{array}{l}\text { No of cases/No of person } \\
\text { years }\end{array}$ & $691 / 470109$ & $127 / 62081$ & $48 / 21582$ & $27 / 12015$ & \\
\hline \multicolumn{6}{|l|}{ Hazard ratio $(95 \% \mathrm{Cl})$ : } \\
\hline Age adjusted & 1.00 & $1.36(1.12$ to 1.65$)$ & $1.42(1.05$ to 1.92$)$ & $1.48(0.99$ to 2.20$)$ & $<0.01$ \\
\hline Multivariable adjusted $\ddagger$ & 1.00 & $1.36(1.12$ to 1.65$)$ & $1.42(1.05$ to 1.93$)$ & $1.54(1.03$ to 2.31$)$ & $<0.01$ \\
\hline
\end{tabular}

*Women who reported PPI use on a biennial questionnaire were assigned a duration of use of 2 years, and this variable increased in biennial increments (thus women who reported PPI use on two biennial questionnaires were assigned a duration of use of 4 years, those who reported use on three questionnaires were assigned a duration of 6 years, etc).

$\dagger P_{\text {trend }}$ was estimated by entering the duration of regular PPI use in the model as a continuous variable.

$\ddagger$ Adjusted for age (months), body mass index, alcohol intake, total energy adjusted calcium intake, history of osteoporosis, level of physical activity, smoking status, vitamin $\mathrm{D}$ intake, bisphosphonate use, thiazide use, corticosteroid use, and use of postmenopausal hormone replacement therapy (see table 2 for details). 
Table $4 \mid$ Risk of hip fracture according to time since stopping use of proton pump inhibitors (PPIs) among 79899 postmenopausal women enrolled in the Nurses' Health Study

\begin{tabular}{|c|c|c|c|c|}
\hline & \multirow[b]{2}{*}{ Never used PPI } & \multicolumn{2}{|c|}{ Stopped PPI use } & \multirow[b]{2}{*}{ Current PPI use } \\
\hline & & $\geq 2$ years ago & $<2$ years ago & \\
\hline No of cases/No of person years & $691 / 470109$ & $13 / 5028$ & $40 / 17017$ & $149 / 73632$ \\
\hline \multicolumn{5}{|l|}{ Hazard ratio $(95 \% \mathrm{Cl})$ : } \\
\hline Age adjusted & 1.00 & $1.09(0.62$ to 1.91$)$ & 1.54 (1.11 to 2.14$)$ & 1.38 (1.15 to 1.66$)$ \\
\hline Multivariable adjusted* & 1.00 & $1.10(0.63$ to 1.92$)$ & $1.53(1.10$ to 2.12$)$ & $1.39(1.15$ to 1.68$)$ \\
\hline
\end{tabular}

*Adjusted for age (months), body mass index, alcohol intake, total energy adjusted calcium intake, history of osteoporosis, level of physical activity, smoking status, vitamin D intake, bisphosphonate use, thiazide use, corticosteroid use, and use of postmenopausal hormone replacement therapy (see table 2 for details). 
Table 5| Risk of hip fracture according to use of proton pump inhibitors (PPI) in selected strata of 79899 postmenopausal women enrolled in the Nurses' Health Study

\section{Stratum \\ Age}

Non-user of PPIs

Regular PPI user

$\mathbf{P}_{\text {interaction }}{ }^{*}$

$\leq 65$ years:

1.00

No of cases/No of person years

$66 / 160861$

$12 / 21360$

Hazard ratio $(95 \% \mathrm{Cl})$.

\begin{tabular}{lcc}
\hline Age adjusted & 1.00 & 1.51 (0.80 to 2.86$)$ \\
\hline Multivariable adjustedt & 1.00 & 1.34 (0.70 to 2.60$)$ \\
\hline$>65$ years: & & \\
\hline No of cases/No of person years & $678 / 331294$ & $137 / 52273$ \\
\hline Hazard ratio $(95 \% \mathrm{Cl}):$ & & \\
\hline Age adjusted & 1.00 & 1.34 (1.10 to 1.61$)$ \\
\hline Multivariable adjusted & 1.00 & 1.36 (1.12 to 1.64$)$
\end{tabular}

\section{Body mass index}

$<25$ :

No of cases/No of person years

$455 / 218797$

Hazard ratio $(95 \% \mathrm{Cl})$

\begin{tabular}{lcc} 
Age adjusted & 1.00 & 1.54 (1.21 to 1.95$)$ \\
\hline Multivariable adjustedt & 1.00 & 1.45 (1.14 to 1.85$)$ \\
\hline$\geq 25:$ & & $64 / 48260$ \\
\hline No of cases/No of person years & $289 / 273357$ & \\
\hline Hazard ratio $(95 \% \mathrm{Cl}):$ & & 1.30 (0.99 to 1.72$)$ \\
\hline Age adjusted & 1.00 & 1.23 (0.93 to 1.64$)$ \\
\hline Multivariable adjustedt & 1.00 &
\end{tabular}

Postmenopausal hormone use

Never or previously used:

No of cases/No of person years

$625 / 350735$

$125 / 54534$

Hazard ratio $(95 \% \mathrm{Cl})$

\begin{tabular}{|c|c|c|c|}
\hline Age adjusted & 1.00 & 1.36 (1.11 to 1.66$)$ & \\
\hline Multivariable adjusted $\dagger$ & 1.00 & $1.36(1.11$ to 1.66$)$ & \\
\hline \multicolumn{4}{|l|}{ Currently used: } \\
\hline No of cases/No of person years & $119 / 141419$ & 24/19 099 & \\
\hline \multicolumn{4}{|l|}{ Hazard ratio $(95 \% \mathrm{Cl})$ : } \\
\hline Age adjusted & 1.00 & 1.44 (0.91 to 2.28$)$ & \\
\hline Multivariable adjusted $\dagger$ & 1.00 & 1.36 (0.84 to 2.19$)$ & \\
\hline \multicolumn{4}{|l|}{ Smoking status } \\
\hline Never: & & & 0.03 \\
\hline No of cases/No of person years & $322 / 220553$ & $49 / 31829$ & \\
\hline \multicolumn{4}{|l|}{ Hazard ratio $(95 \% \mathrm{Cl})$ : } \\
\hline Age adjusted & 1.00 & 1.07 (0.78 to 1.45$)$ & \\
\hline Multivariable adjusted $\dagger$ & 1.00 & $1.06(0.77$ to 1.46$)$ & \\
\hline \multicolumn{4}{|l|}{ Current or past: } \\
\hline No of cases/No of person years & $422 / 271600$ & $100 / 41803$ & \\
\hline \multicolumn{4}{|l|}{ Hazard ratio $(95 \% \mathrm{Cl})$ : } \\
\hline Age adjusted & 1.00 & 1.54 (1.23 to 1.93$)$ & \\
\hline Multivariable adjusted $\dagger$ & 1.00 & $1.51(1.20$ to 1.91$)$ & \\
\hline \multicolumn{4}{|l|}{ Corticosteroid use } \\
\hline User: & & & 0.10 \\
\hline No of cases/No of person years & $71 / 29054$ & $40 / 9816$ & \\
\hline
\end{tabular}

Hazard ratio $(95 \% \mathrm{Cl})$ : 
Table 5 (continued)

\begin{tabular}{|c|c|c|c|}
\hline Stratum & Non-user of PPIs & Regular PPI user & $\mathbf{P}_{\text {interaction }}{ }^{*}$ \\
\hline Age adjusted & 1.00 & $1.87(1.22$ to 2.86$)$ & \\
\hline Multivariable adjusted $\dagger$ & 1.00 & 2.09 (1.32 to 3.30$)$ & \\
\hline \multicolumn{4}{|l|}{ Non-user: } \\
\hline No of cases/No of person years & $673 / 463101$ & $109 / 63817$ & \\
\hline \multicolumn{4}{|l|}{ Hazard ratio $(95 \% \mathrm{Cl})$ : } \\
\hline Age adjusted & 1.00 & $1.19(0.97$ to 1.47$)$ & \\
\hline Multivariable adjusted $\dagger$ & 1.00 & $1.26(1.02$ to 1.55$)$ & \\
\hline \multicolumn{4}{|l|}{ History of osteoporosis } \\
\hline Yes: & & & 0.76 \\
\hline No of cases/No of person years & $392 / 353613$ & $62 / 45687$ & \\
\hline \multicolumn{4}{|l|}{ Hazard ratio $(95 \% \mathrm{Cl})$ : } \\
\hline Age adjusted & 1.00 & 1.25 (0.98 to 1.60$)$ & \\
\hline Multivariable adjusted $\dagger$ & 1.00 & 1.28 (1.00 to 1.64$)$ & \\
\hline \multicolumn{4}{|l|}{ None: } \\
\hline No of cases/No of person years & $352 / 138542$ & $87 / 27945$ & \\
\hline \multicolumn{4}{|l|}{ Hazard ratio $(95 \% \mathrm{Cl})$ : } \\
\hline Age adjusted & 1.00 & 1.31 (1.00 to 1.73$)$ & \\
\hline Multivariable adjusted $\dagger$ & 1.00 & $1.41(1.07$ to 1.87$)$ & \\
\hline \multicolumn{4}{|l|}{ Calcium intake } \\
\hline$\geq 900 \mathrm{mg} /$ day: & & & 0.38 \\
\hline No of cases/No of person years & $371 / 274346$ & $79 / 42070$ & \\
\hline \multicolumn{4}{|l|}{ Hazard ratio $(95 \% \mathrm{Cl})$ : } \\
\hline Age adjusted & 1.00 & 1.41 (1.10 to 1.82$)$ & \\
\hline Multivariable adjusted $\dagger$ & 1.00 & $1.42(1.10$ to 1.83$)$ & \\
\hline \multicolumn{4}{|l|}{$<900$ mg/day: } \\
\hline No of cases/No of person years & $373 / 217810$ & 70/31 563 & \\
\hline \multicolumn{4}{|l|}{ Hazard ratio $(95 \% \mathrm{Cl})$ : } \\
\hline Age adjusted & 1.00 & $1.26(0.97$ to 1.64$)$ & \\
\hline Multivariable adjusted $\dagger$ & 1.00 & $1.25(0.95$ to 1.64$)$ & \\
\hline
\end{tabular}

*We evaluated effect modification using cross classified categories of hip fracture risk factors and PPI use. We tested significance of interactions using the log-likelihood ratio test comparing the model with cross classified categories with a model that included the risk factors as independent variables. †Adjusted for same variables as Table 3 minus the stratum covariate. 


\section{Figure}

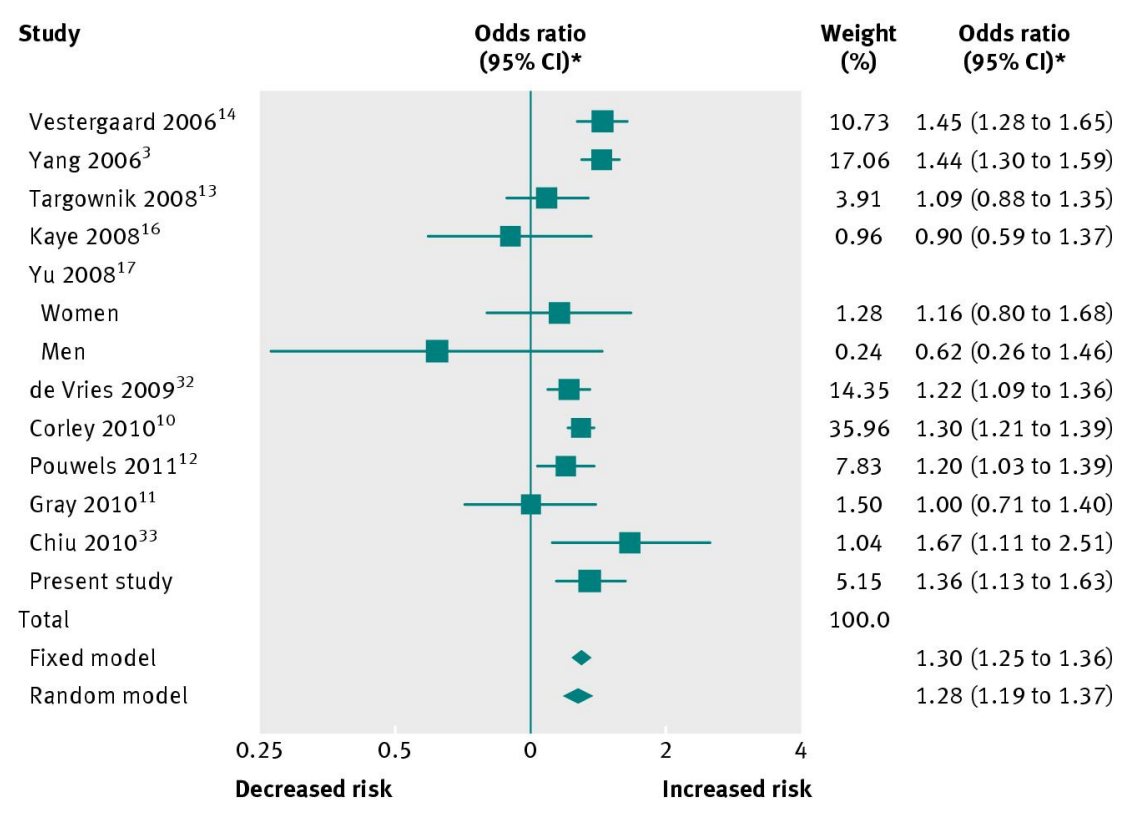

*Hazard ratios used for Yu $2008^{17}$

Results of meta-analysis of our results with 10 published studies of risk of hip fracture with chronic use of a proton pump inhibitor (PPI). For the study by Yu et al, ${ }^{13}$ risk estimates were only provided for men and women separately 